\title{
Autopsy Findings in a Case of Ellis Van Creveld Syndrome with Review of Literature
}

\author{
Asaranti Kar*, Dilleswari Pradhan, Jagannath Pahi, Mrunmayee Patra, Pranati Mohanty, \\ Gayatri Rath, Susmita Behera
}

Department of Pathology, S.C.B. Medical College, Cuttack, India

Email: asarantikar@yahoo.co.in

Received 18 May 2014; revised 15 June 2014; accepted 14 July 2014

Copyright (C) 2014 by authors and Scientific Research Publishing Inc.

This work is licensed under the Creative Commons Attribution International License (CC BY).

http://creativecommons.org/licenses/by/4.0/

(c) (i) Open Access

\begin{abstract}
Ellis Van Creveld (EVC) syndrome is one of the congenital anomalies not compatible with life. It is also known as chondroectodermal dysplasia. The most common manifestations of this syndrome are short ribs, postaxial polydactyly, growth retardation, and ectodermal and cardiac defects. It has an incidence of one in every $\mathbf{6 0 , 0 0 0}$ live births and equal sex predisposition. In our case, perinatal autopsy was performed in a stillborn baby of 32 weeks of gestation having syndactyly, polydactyly and short forearms to know the cause of death and the diagnosis emerged as EVC syndrome. It is important to diagnose EVC syndrome as it is transmitted as an autosomal recessive disorder, so genetic counseling is required to make parents aware of the risk of recurrence.
\end{abstract}

\section{Keywords}

Ellis Van Creveld Syndrome, Perinatal Autopsy, Polydactyly

\section{Introduction}

Ellis Van Creveld syndrome is a rare genetic disorder of skeletal dysplasia type. Richard W. B. Ellis of Edinburg and Simson Van Crevald of Amsterdam first described EVC syndrome in 1940. The cardinal features usually present as a combination of: 1) disproportionate small stature with increasing severity from the proximal to distal portions of the limbs; 2) polydactyly, affecting hands and occasionally the feet; 3) hydrotic ectodermal dysplasia mainly affecting the nails, hair and teeth; 4) congenital heart malformations occurring in about 50\% - 60\% of cases and comprising of single atrium, defects of the mitral and tricuspid valves, patent ductus, ventricular

${ }^{*}$ Corresponding author.

How to cite this paper: Kar, A., Pradhan, D., Pahi, J., Patra, M., Mohanty, P., Rath, G. and Behera, S. (2014) Autopsy Findings in a Case of Ellis Van Creveld Syndrome with Review of Literature. International Journal of Clinical Medicine, 5, 851-854. http://dx.doi.org/10.4236/ijem.2014.514114 
septal defect, atrial septal defect and hypoplastic left heart syndrome, the most common being interseptal defects [1]. The presence of congenital heart disease may support the diagnosis of the EVC syndrome and appears to be the main determinant of longevity [2]. Oral manifestations include congenitally missing primary and permanent teeth, microdontia, supernumerary teeth and abnormal tooth morphology. Herein, we are presenting this case as it is a rare genetic disorder with an incidence of 1 in 60,000 live births [3]. Only about 150 cases have been described in the world literature and perinatal death due to EVC syndrome has rarely been described in the Indian literature [2]. Also the present case has additional abnormalities like imperforate anus and absence of bilateral kidneys. These were discovered during the detail autopsy study thereby proving the importance of autopsy in all cases of perinatal deaths especially if it is due to multiple congenital malformations.

\section{Case Report}

A 36-year-old primi with 32 weeks of pregnancy presented with pain abdomen and absence of fetal movement since 2 days. She was married for 3 years and her marriage was non-consanguinous. Ultrasonography revealed single dead fetus of 32 weeks gestation, absence of right kidney and oligohydramnios of mother. She delivered a still born baby vaginally.

Autopsy was performed following standard protocol. On external examination, weight of the baby was 900 gm, crown heal length $-37 \mathrm{~cm}$, crown rump length $-28 \mathrm{~cm}$, head and chest circumference $30 \mathrm{~cm}$ and $27 \mathrm{~cm}$ respectively and foot length was $5 \mathrm{~cm}$. Placenta was normal and umbilical cord did not show any knotting or stricture. The baby had very short forearms (Figure 1), syndactyly and polydactyly (6 toes) in the left foot (Figure 2), left and right thumbs rudimentary, finger nail dysplasia, flat pinna, imperforate anus (Figure 3). $\mathrm{X}$-ray of the dead baby showed absence of radius in the left forearm (Figure 4). Dissection was done by giving a modified "Y" shaped incision from below the ear till symphysis pubis encircling the umbilicus on left side. Internal examination showed atrial septal defect (ASD) and absence of kidneys in both sides. Histopathological study after formalin fixation using H\&E stain from different tissues failed to detect any obvious abnormality except chondrocytic degeneration. After reviewing the literature and considering all the clinical features and the skeletal survey of the still born baby the final autopsy diagnosis was made as Ellis Van Creveld syndrome. Genetic study was not done due to lack of facility.

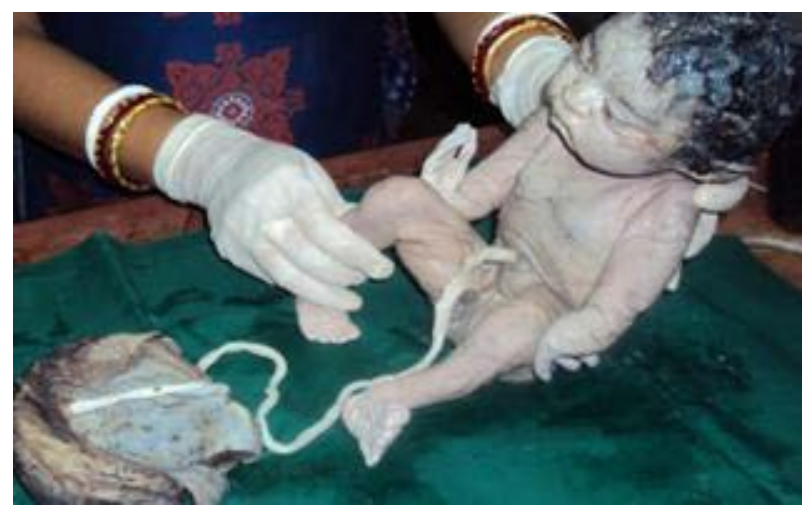

Figure 1. Baby with placenta, short fore arms.

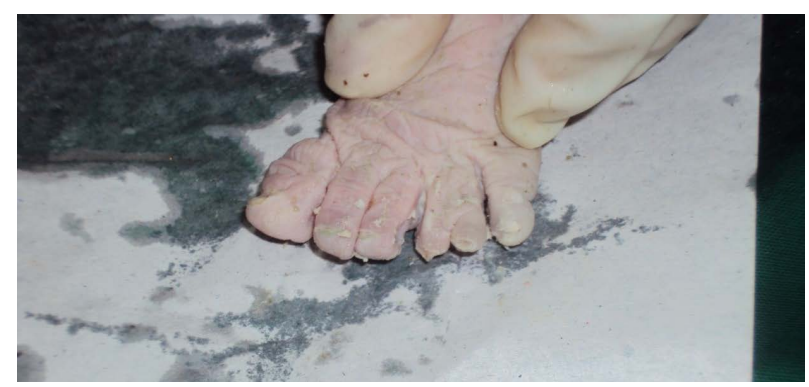

Figure 2. Syndactyly and polydactyly of left foot. 


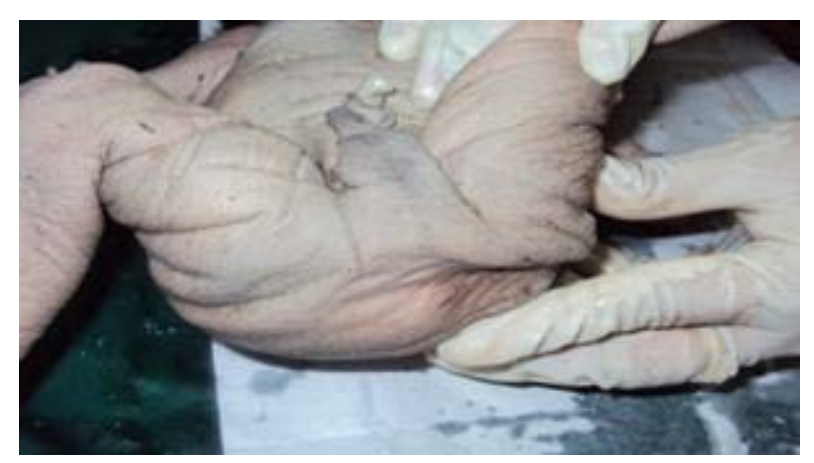

Figure 3. Imperforate anus.

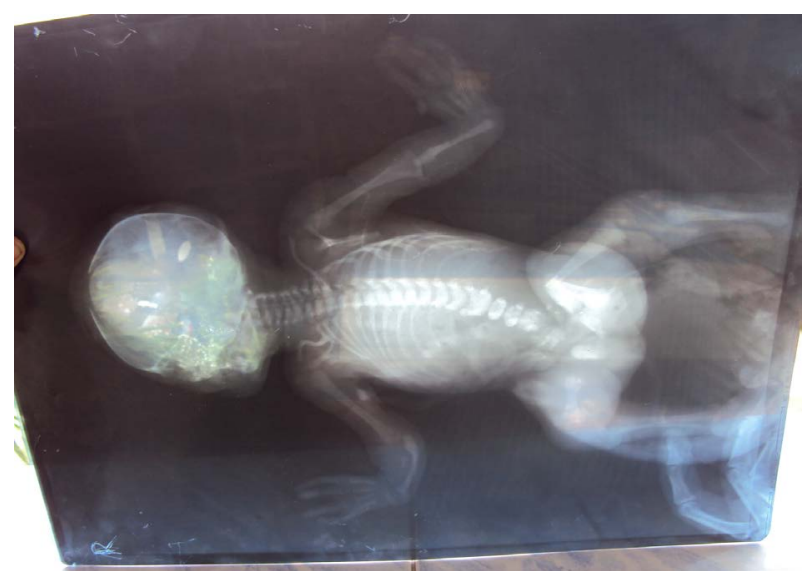

Figure 4. X-ray picture showing short limbs with absence of radius in upper arm.

\section{Discussion}

EVC syndrome is a disease complex where all the three embryonic layers appear to be involved. It is transmitted by autosomal recessive trait. Mutation of EVC1 and EVC2 genes, located in a head to head configuration on chromosome 4p16 have been identified as causative focus [4]. The largest pedigree of EVC syndrome has been described in the old order Amish community in Lancaster country, Pennsylvania [5]. EVC syndrome belongs to the short rib polydactyly [SRP] group. These SRP, especially Type 3 [Verma Naumoff syndrome] are discussed in the prenatal differential diagnosis [2]. Recently EVC syndrome has been included in a new class of human genetic disorder called ciliopathies, where the underlying defect may be dysfunctional molecular mechanism in the primary cilia of the cells. Prenatal consanguinity has been confirmed in about 30 cases [6].

Chondrodystrophy is the most common clinical feature, affecting the tubular bones producing a serious ossification defect. In consequence, the distal part of the limbs are small, leading to short stature. Congenital heart malformations are described in $50 \%$ to $60 \%$ of patients affected by this syndrome. Defects of the mitral and tricuspid valves, patent ductus arteriosus, ventricular septal defects and atrial septal defects are some of the malformations described as the principal cause of decreased life-expectancy in these patients. Additional clinical findings affecting other organs (lungs, kidneys, liver, pancreas and central nervous system) may occasionally be observed. Genitourinary anomalies such as agenesis and renal dysplasia, ureter ectasia and nephrocalcinosis usually present in $20 \%$ of cases. In our case the baby had syn and polydactyly, absence of radius in forearm, finger nail dysplasia and atrial septal defect fulfilling all the features of clinical tetrad. The baby was small for gestational age as per the measurements and died in utero. Ellis Van Creveld syndrome can be diagnosed during the prenatal period, starting from the 18th week of gestation, by ultrasonography [7]. But in the said case even though the mother had antenatal ultrasonography it failed to detect the abnormality except absence of one kidney and oligohydramnios of mother. Molecular genetic testing (DNA mutation analysis) can be done by amniocentesis or chorionic villi biopsy [8]. 
Differential diagnosis includes Jeune syndrome and Orofaciodigital syndromes [9]. Jeune syndrome is a rare, potentially lethal, autosomal recessive disease; characterized by thoracic dystrophy, short limbs, small stature, polydactyly and generalized bony dysplasia. There are anomalies in pigmentation of the retina, renal involvement and hypoplastic lungs [10]. The orofaciodigital syndromes result from dominant sex-linked inheritance, are limited to women. This is clinically characterized by multiple gingivolabial frenula, hypoplasia of the nasal cartilages, moderate mental retardation and fissured tongue. Ankyloglossia is found in one third of such cases [11]. $50 \%$ of patients of Ellis Van Creveld syndrome die in infancy due to thoracic dysplasia leading to respiratory insufficiency and cardiac anomalies. Patients who survive infancy have a normal life expectancy.

\section{Conclusions}

The birth of a congenitally deformed child imparts strong social stigma over the parents. Though this syndrome is a rare entity, prenatal diagnosis may be possible by use of ultrasonography. Genetic screening is not required to detect but genetic counseling is required to make the parents aware of the risk of recurrence. An early diagnosis of EVC syndrome and therapeutic care with a multidisciplinary approach will warrant these patients in achieving a better quality of life.

In the present case though ultrasonography was done, it could not detect the anomaly with confirmation. Finding of short limbs, absence of bilateral kidneys (not only one kidney) could not be detected by imaging. This proves the importance of autopsy over imaging studies and the authors strongly suggest conducting a detail autopsy study in all cases of perinatal deaths to confirm and/or detect the different congenital malformations and also for counseling of parents about further pregnancies.

\section{References}

[1] Ruiz Perez, V.L., et al. (2003) Mutations in Two Nonhomologous Genes in a Head to Head Configuration Cause Ellis Van Creveld Syndrome. American Journal of Human Genetics, 72, 728-732. http://dx.doi.org/10.1086/368063

[2] Baujat, G., et al. (2007) Ellis Van Creveld Syndrome. Orphanet Journal of Rare Diseases, 2, 27. http://dx.doi.org/10.1186/1750-1172-2-27

[3] Jayaraj, D., et al. (2012) Ellis Van Creveld Syndrome. Journal of Pharmacy \& Bioallied Sciences, 4, s153-s156. http://dx.doi.org/10.4103/0975-7406.100257

[4] (1998) Ellis Van Creveld Syndrome. Genes and Diseases. NCBI.

[5] Arya, L., Mendiratta, V., Sharma, R.C. and Solanki, R.S. (2001) Ellis-Van Creveld Syndrome: A Report of Two Cases. Pediatric Dermatology, 18, 485-489. http://dx.doi.org/10.1046/j.1525-1470.2001.1861994.x

[6] Atasu, M. and Biren, S. (2000) Ellis-Van Creveld Syndrome: Dental, Clinical, Genetic and Dermatoglyphic Findings of a Case. Journal of Clinical Pediatric Dentistry, 24, 141-145.

[7] Digoy, G.P., Greenberg, M. and Magit, A. (2005) Congenital Stridor Secondary to an Upper Airway Cyst in a Patient with Ellis-Van Creveld Syndrome. International Journal of Pediatric Otorhinolaryngology, 69, 1433-1435. http://dx.doi.org/10.1016/j.ijporl.2005.04.003

[8] Baujat, G. and Le Merrer, M. (2007) Ellis-Van Creveld Syndrome. Orphanet Journal of Rare Diseases, 2, 27. http://dx.doi.org/10.1186/1750-1172-2-27

[9] Ruiz-Perez, V.L., Ide, S.E., Strom, T.M., Lorenz, B., Wilson, D., Woods, K., et al. (2000) Mutations in a New Gene in Ellis-Van Creveld Syndrome and Weyers Acrodental Dysostosis. Nature Genetics, 24, 283-286. http://dx.doi.org/10.1038/73508

[10] Tompson, S.W., Ruiz-Perez, V.L., Blair, H.J., Barton, S., Navarro, V., Robson, J.L., et al. (2007) Sequencing EVC and EVC2 Identifies Mutations in Two-Thirds of Ellis-Van Creveld Syndrome Patients. Human Genetics, 120, 663-670. http://dx.doi.org/10.1007/s00439-006-0237-7

[11] Ghosh, S., Setty, S., Sivakumar, A. and Pai, K.M. (2007) Report of a New Syndrome: Focus on Differential Diagnosis and Review of Ellis-Van Creveld, Curry-Hall, Acrofacial Dysostosis, and Orofacial Digital Syndromes. Oral Surgery, Oral Medicine, Oral Pathology, Oral Radiology, and Endodontology, 103, 670-676.

http://dx.doi.org/10.1016/j.tripleo.2006.02.028 
Scientific Research Publishing (SCIRP) is one of the largest Open Access journal publishers. It is currently publishing more than 200 open access, online, peer-reviewed journals covering a wide range of academic disciplines. SCIRP serves the worldwide academic communities and contributes to the progress and application of science with its publication.

Other selected journals from SCIRP are listed as below. Submit your manuscript to us via either submit@scirp.org or Online Submission Portal.
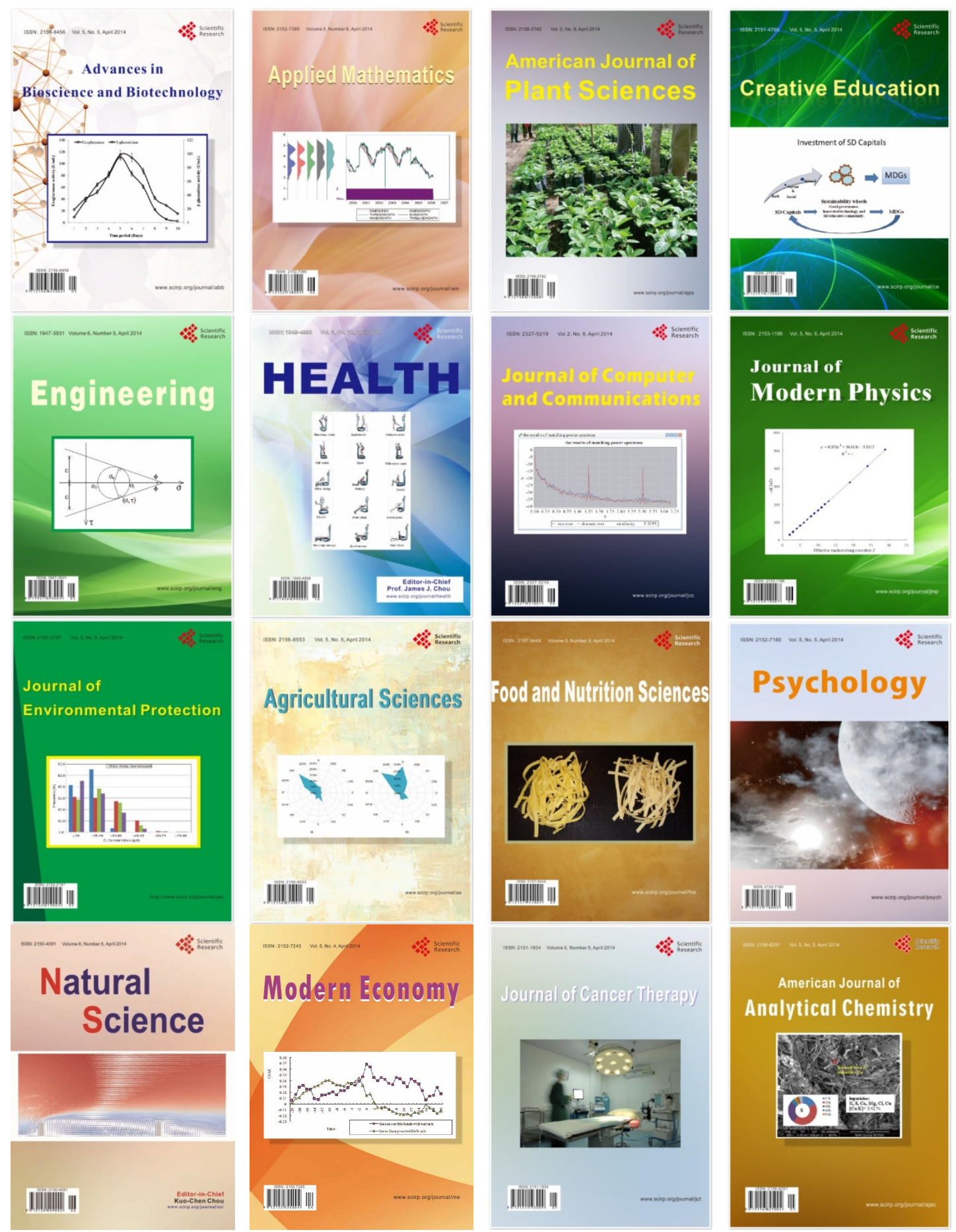